\title{
CONTINUOUS PROFESSIONAL DEVELOPMENT
}

\section{Importance of first trimester scan - 2 of 4}

\section{Twin pregnancy}

\author{
Tiran Dias ${ }^{1}$
}

Sri Lanka Journal of Obstetrics and Gynaecology 2011; 33: 72-76

\section{Introduction}

Twin pregnancies have a greater incidence of perinatal morbidity and mortality, primarily attributed to the uteroplacental insufficiency, premature births and antepartum complications ${ }^{1}$. Monochorionic (MC) twins account for $20 \%$ of all spontaneous twin pregnancies, but yet carry five time higher perinatal morbidities and mortalities than dichorionic (DC) twins ${ }^{2-3}$. This is due to the presence of placental vascular anastomoses allowing interfetal transfusion, which accounts for the $15-20 \%$ of twintwin transfusion syndrome (TTTS) and a further 25\% of severe birthweight discordances ${ }^{4}$. Moreover, most of the complications in monochorionic twins are early onset (before 20 weeks) and if not treated majority of them will die before 25 weeks. Additionally, in the event of a single-twin intrauterine death (IUD), the acute intertwin transfusion poses a more profound risk for the surviving $\mathrm{MC}$ twin than for the DC twin ${ }^{5}$. Consequences for the surviving co-twin include severe neurological impairment, death and premature delivery ${ }^{5}$. Therefore it is vital to determine the chorionicity in the first trimester.

\section{Determination of chorionicity}

Chorionicity can be accurately determined during first trimester ultrasonography. Monochorionic twin pregnancy can be diagnosed in the presence of the T-sign and dichorionic with the $\lambda$-sign or when two separate placental masses are present ${ }^{6-7}$ (Figures 1 and $2)$. The $\lambda$-sign was first described by Bessis and Papernik (1981), and referred to the triangular tissue projection extending from the base of the inter-twin membrane in early dichorionic pregnancies with a single fused placenta ${ }^{8}$. The term $\lambda$-sign has been used interchangeably with the 'twin peak' sign 9 . The absence of the $\lambda$-sign leads to the finding of the T-sign characteristic of monochrorionicity. Largest study of the accuracy of the $T / \lambda$-signs and number of placentas

\footnotetext{
${ }^{1}$ Senior Lecturer in Obstetrics and Gynaecology, Department of Obstetrics and Gynaecology, Faculty of Medicine, University of Colombo, Sri Lanka.

E-mail: thiran_dias@yahoo.com
}

in the first trimester diagnosis of chorionicity has shown that chorionicity determination is feasible and very accurate at 11 to 14 weeks gestation ${ }^{7}$. Dias et al in that study reported the sensitivity of $T / \lambda$-signs and number of placentas for the detection of monochrorionicity was $100 \%$ with only one dichorionic pregnancy incorrectly assigned as monochorionic ${ }^{7}$.

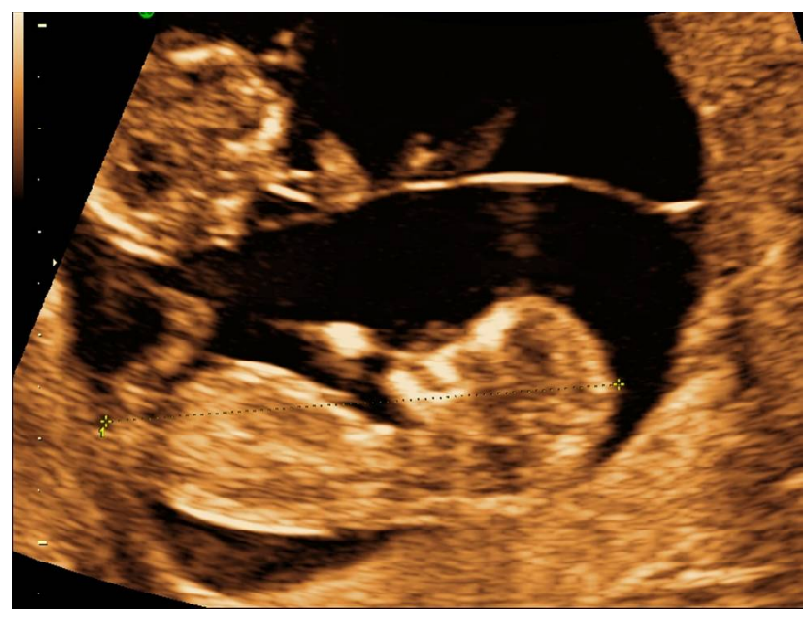

Figure 1. ' $\mathrm{T}$ ' sign in monochorionic twin pregnancy.

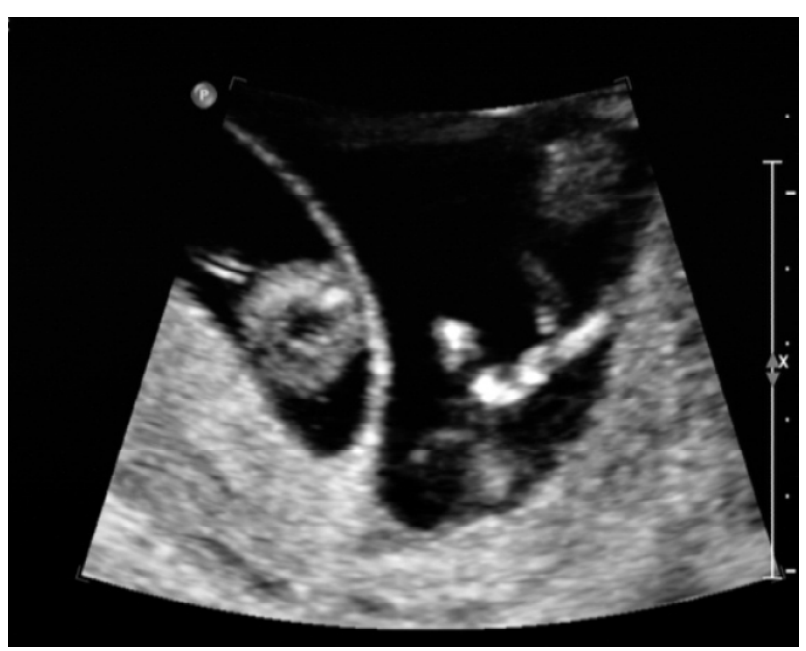

Figure 2. Lambda sign ( $\lambda$-sign) in dichorionic twin pregnancy. 


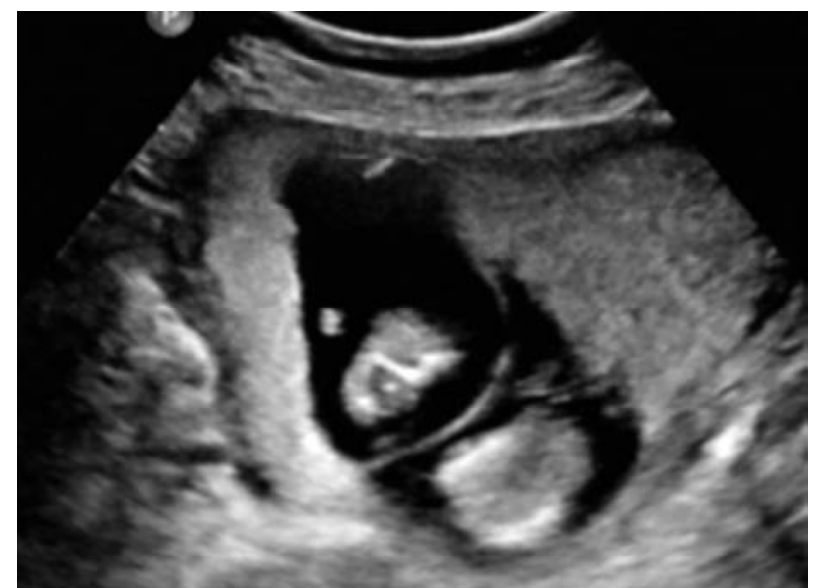

Figure 3. Two different placental mass in dichorionic twins.

As the pregnancy advances into the second trimester, regression of the chorion frondosum leads to the gradual loss of the $\lambda$-sign. This change explains the observation that the $\lambda$-sign is not visible in about $7 \%$ of dichorionic pregnancies by 20 weeks' gestation ${ }^{10}$. Therefore, it is mandatory to assign chorionicity in the first trimester. If there is uncertainty about the chorionicity, thermal image of the membrane attachment to the placenta should be retained in the case notes and a second opinion should be sought or the woman should be referred to a specialist without delay, as chorionicity is best determined before 14 weeks (RCOG) $)^{11}$.

\section{Twin pregnancy dating}

Routine dating of pregnancy from a first trimester crown-rump length (CRL) is superior to the use of menstrual dates ${ }^{12-14}$. Accurate dating of twin pregnancies is vital as twin pregnancies are at increased risk of perinatal morbidity and mortality compared to singletons, mainly as a consequence of both preterm delivery and fetal growth restriction.
There are two main concerns in twin pregnancy dating. Firstly, whether CRL charts derived from singleton pregnancies can be used to accurately date twin pregnancy. Secondly, which twin's measurement should be considered for dating? Dias et al concluded that singleton CRL charts can be used reliably to date twin pregnancy with the difference of 1-2 days (Table 1$)^{15}$. Furthermore, larger twin's CRL is more pragmatic for dating as pathological largeness in early pregnancy is not biologically plausible but smallness ${ }^{15}$. After 14 weeks as for singletons, head circumference can be reliably used for twin pregnancy dating in second trimester up to 25 weeks $^{19}$.

\section{Twin pregnancy orientation}

A reproducible method for antenatal labeling of twins is important in the management of all twin pregnancies. This is to ensure that biometry from longitudinal growth scans are consistently allocated to the same twin at each visit. Inconsistent allocation of twin in each visit may result in the 'yo-yoing' of fetal growth as smaller and larger twin sizes are swapped repeatedly during the course of the pregnancy. Additionally, when screening for aneuploidies is undertaken, there must be a reliable and accurate system in place to ensure that invasive prenatal diagnosis or selective fetal reduction is carried out on the at-risk or affected twin, respectively ${ }^{11}$. Each fetus within the twin pregnancy can be orientated at the 11-14 week ultrasound assessment, the fetus contained in the gestational sac closest to the maternal cervix is designated as twin one $\mathrm{e}^{20,21}$. The relative orientation of the fetuses to each other (Figures 4 and 5 ) is then defined as either lateral (left/right) or vertical (top/bottom). Lateral fetal orientation is associated with an inter-twin membrane running vertically along the longitudinal axis of the uterus and a vertical fetal orientation is associated with an inter-twin membrane running horizontally across the longitudinal axis of the uterus (Figures 4 and 5).

Table 1. The mean difference between observed (from ultrasound) and expected (from IVF history) measurements expressed in days with $95 \%$ confidence interval in parentheses ${ }^{15}$ (Dias et al)

\begin{tabular}{lccc}
\hline CRL formulae & \multicolumn{3}{c}{ Mean difference in gestation (days) } \\
\cline { 2 - 3 } & Singleton & Bigger twin & Smaller twin \\
\hline Robinson $^{16}$ & 1.41 days & 2.4 days & 0.91 days \\
& $(1.15$ to 1.68$)$ & $(2.4$ to 2.6$)$ & $(0.55$ to 1.30$)$ \\
Rossavik $^{17}$ & 0.14 days & 1.27 days & -0.51 days \\
& $(0.01$ to 0.28$)$ & $(1.05$ to 1.5$)$ & $(-0.30$ to -0.72$)$ \\
Von Kaisenberg18 $^{18}$ & -0.54 days & 0.58 days & -1.18 days \\
& $(-0.41$ to -0.67$)$ & $(0.36$ to 0.8$)$ & $(-0.97$ to -1.4$)$ \\
\hline
\end{tabular}




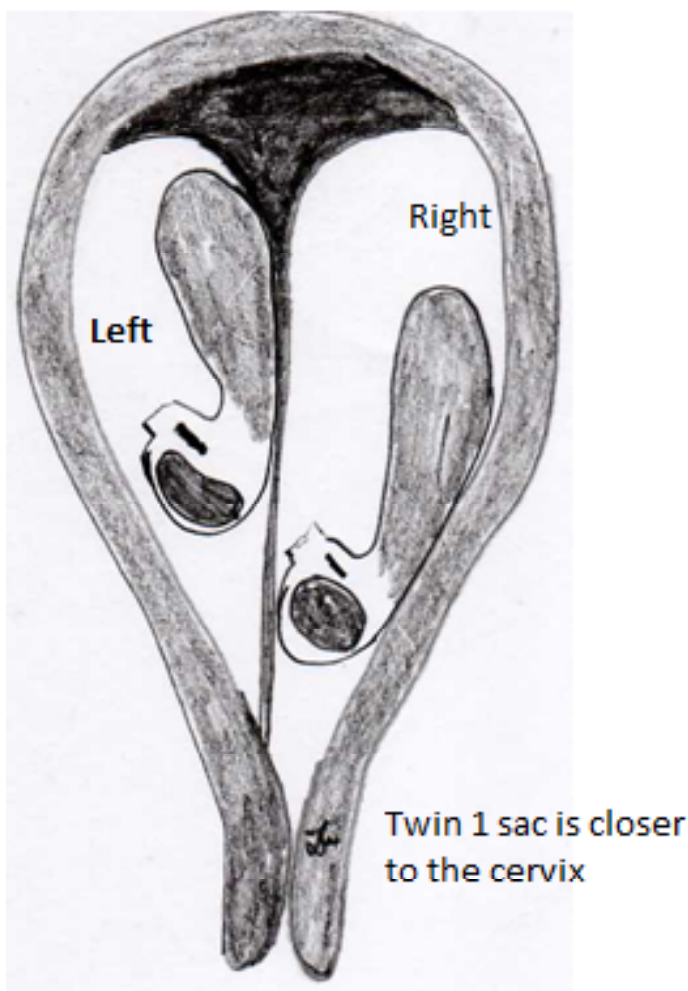

Figure 4. Diagrammatic representation of twin orientation relative to the longitudinal axis of the uterus - left/right orientation.

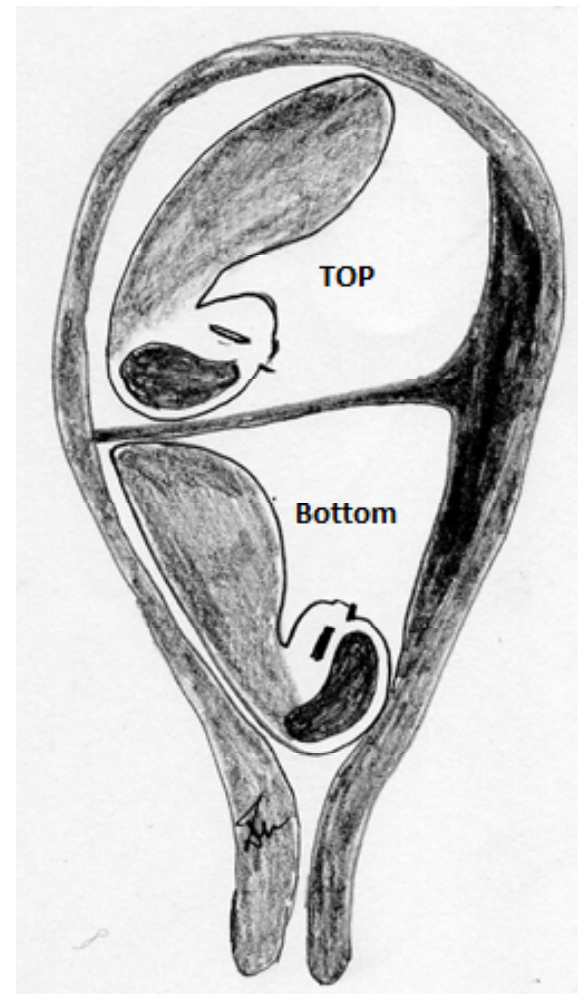

Figure 5. Diagrammatic representation of twin orientation relative to the longitudinal axis of the uterus - top/bottom orientation.

Table 2. Risk of trisomy 21 at 12 weeks

\begin{tabular}{lrrr}
\hline Age (yrs) & \multicolumn{3}{c}{ Risk for trisomy 21 at 12 weeks } \\
\cline { 2 - 4 } 20 & 1100 & Monozygotic & Dizygotic \\
25 & 1000 & 1100 & 550 \\
30 & 650 & 1000 & 500 \\
31 & 550 & 650 & 325 \\
32 & 450 & 550 & 275 \\
33 & 400 & 450 & 225 \\
34 & 300 & 400 & 200 \\
35 & 250 & 300 & 150 \\
36 & 200 & 250 & 125 \\
37 & 150 & 200 & 100 \\
38 & 120 & 150 & 75 \\
39 & 90 & 120 & 60 \\
40 & 70 & 90 & 45 \\
41 & 50 & 70 & 35 \\
42 & 40 & 50 & 25 \\
\hline
\end{tabular}




\section{Aneuploidy screening in twin pregnancy}

Risk of underlying chromosomal problems in each fetus depends on zygocity. In dizygotic twins the maternal age-related risk for chromosomal abnormalities for each fetus is the same as in singleton pregnancies. As majority of dichorionic twins are dizygotic the chance that at least one fetus is affected by a chromosomal defect is twice as high as in singleton pregnancies. Since all the monochorionic twins are monozygotic their risk for a chromosomal abnormality affecting both fetuses is the same as in singleton pregnancies (Table 2).

Risk assessment for chromosomal abnormalities in twin pregnancies can be effectively done by a combination of maternal age, fetal NT thickness, FHR and maternal serum free $\beta$-hCG and PAPP-A ${ }^{22-23}$. Most importantly standardized values of serum biochemistry should be used in the risk calculation formula in twin pregnancy ${ }^{23}$.

In dichorionic twins the fetus specific risk for trisomy 21 is determined by the differences in NT. The detection rate $(>90 \%)$ and false positive rate $(3 \%$ per fetus or $6 \%$ per pregnancy) are similar to those in singleton pregnancies ${ }^{22}$.

Increased NT in at least one of the fetuses could be an early manifestation of TTTS in Monochorionic twins ${ }^{24}$. Therefore, the false positive rate of screening (8\% per pregnancy) is higher than in DC twins. As all monochorionic twins are monozygotic, they invariably concordant for fetal karyotype. In monochorionic twins the risk for trisomy ${ }^{21}$ is calculated for each fetus, based on maternal age, fetal NT and maternal serum biochemistry and then the average risk between the two fetuses is considered to be the risk for the pregnancy as a whole ${ }^{25}$.

Amniocentesis in twins is effective in providing a reliable karyotype for both fetuses and the procedurerelated fetal loss rate is about $2 \%$. In the case of chorionic villous sampling, the procedure-related fetal loss rate is also about $2 \%$, but in about $1 \%$ of cases there may be a diagnostic error, either due to sampling the same placenta twice or cross-contamination.

In pregnancies discordant for chromosomal defects the main options are either selective fetocide or expectant management. Selective fetocide after 16 weeks of gestation is associated with three-fold increase in risk of spontaneous abortion compared to reduction before 16 weeks. Consequently, if the parents request invasive testing it is preferable to perform CVS rather than amniocentesis.

\section{References}

1. Sherer DM. Adverse perinatal outcome of twin pregnancies according to chorionicity: review of the literature. American Journal of Perinatology 2001; 18: 23-37.
2. Dias T, Bhide A, Thilaganathan B. Early pregnancy growth and pregnancy outcome in twin pregnancies. Ceylon Med J 2010; 55(3): 80-4.

3. Acosta-Rojas R, Becker J, Munoz-Abellana B, et al. Twin chorionicity and the risk of adverse perinatal outcome. International Journal of Obstetrics and Gynaecology 2007; 96: 98-102.

4. Barigye $\mathrm{O}$, Pasquini L, Galea $\mathrm{P}$, et al. High risk of unexpected late fetal death in monochorionic twins despite intensive ultrasound surveillance: a cohort study. PLoS Medicine 2005; 2(6): e172.

5. Ong SS, Zamora J, Khan KS, Kilby MD. Prognosis for the co-twin following single-twin death: a systematic review. BJOG 2006; 113: 992-8.

6. Sepulveda W, Sebire NJ, Hughes K, Odibo A, Nicholaides $\mathrm{KH}$. The lambda sign at 10-14 weeks of gestation as a predictor of chorionicity in twin pregnancies. Ultrasound Obstet Gynecol 1996; 7: 421-3.

7. Dias T, Arcangeli T, Bhide A, Napolitano R, MahsudDornan S, Thilaganathan B. First-trimester ultrasound determination of chorionicity in twin pregnancy. Ultrasound Obstet Gynecol 2011 Jan 31. doi: 10.1002/uog.8956.

8. Bessis R, Papernik E. Echographic imagery of amniotic membranes in twin pregnancies. Twin Research 3: Twin Biology and Multiple Pregnancy. Alan R Liss: New York; 1981: 183-7.

9. Finberg HJ. The 'twin peak' sign: reliable evidence of dichorionic twinning. J Ultrasound Med 1992; 11: 571-7.

10. Sepulveda W. Chorionicity determination in twin pregnancies: double trouble. Ultrasound Obstet Gynecol 1997; 10: $79-81$.

11. Royal College of Obstetricians and Gynaecologists. Greentop Guideline No. 51. Management of monochorionic twin pregnancy, December 2008.

12. Neilson JP. Ultrasound for fetal assessment in early pregnancy. Cochrane Database of Systematic Reviews 2001, Issue 2. Art. No.: CD000182. DOI: 10.1002/ 14651858.CD000182.

13. Taipale P, Hiilesmaa V. Predicting delivery date by ultrasound and last menstrual period in early gestation. Obstet Gynecol 2001; 97: 189-94.

14. Mongelli M, Wilcox M, Gardosi J. Estimating the date of confinement. Am J Obstet Gynecol 1996; 174: 278-81.

15. Dias T, Mahsud-DornanS, Thilaganathan B, Papageorghiou A, Bhide A. First-trimester ultrasound dating of twin pregnancy: are singleton charts reliable? BJOG 2010; 117(8): 979-84. Epub 2010 May 19.

16. Robinson HP, Fleming JEE. A critical evaluation of sonar "crown-rump length" measurements. BJOG 1975; 82: 702-10.

17. Von Kaisenberg CS, Fritzer E, Kuhling H, Jonat W. Fetal transabdominal biometry at 11-14 weeks of gestation. Ultrasound Obstet Gynecol 2002; 20: 564-74.

18. Rossavik IK, Torjusen GO, Gibbons WE. Conceptual age and ultrasound measurements of gestational sac and crownrump length in in vitro fertilization pregnancies. Fertil Steril 1988; 49: 1012-7. 
19. Dias T, Arcangeli T, Bhide A, Mahsud-Dornan S, Papageorghiou A, Thilaganathan B. Second-trimester assessment of gestational age in twins: validation of singleton biometry charts. Ultrasound Obstet Gynecol 2011; 37(1): 34-7.

20. Chudleigh T, Thilaganathan B. First trimester ultrasound. In Obstetric Ultrasound: How, Why and When (3rd edn), Elsevier, Churchill Livingston: London, 2004; 29-49.

21. Dias T, Ladd S, Mahsud-Dornan S, Bhide A, Papageorghiou AT, Thilaganathan B. Systematic labelling of twin pregnancies on ultrasound: limitations and guidance. Ultrasound Obstet Gynecol 2011 Mar 11. doi: 10.1002/ uog.8990. [Epub ahead of print]

22. Wright D, Syngelaki A, Staboulidou I, Cruz Jde J, Nicolaides $\mathrm{KH}$. Screening for trisomies in dichorionic twins by measurement of fetal nuchal translucency thickness according to the mixturemode. Prenat Diagn 2011; 31(1): 16-21. doi: $10.1002 /$ pd.2643.

23. Spencer K, Kagan KO, Nicolaides KH. Screening for trisomy 21 in twin pregnancies in the first trimester: an update of the impact of chorionicity on maternal serum markers. Prenat Diagn 2008; 28(1): 49-52.

24. Kagan KO, Gazzoni A, Sepulveda-Gonzalez G, Sotiriadis A, Nicolaides KH. Discordance in nuchal translucency thickness in the prediction of severe twin-to-twin transfusion syndrome. Ultrasound Obstet Gynecol 2007; 29(5): 527-32.

25. Cleary-Goldman J, Berkowitz RL. First trimester screening for Down syndrome in multiple pregnancy. Semin Perinatol 2005; 29(6): 395-400.

\section{Subscription Information \\ ISSN 1391-7536}

\section{Subscription rates}

Individual copies - Rs $300 /=$

Subscription for one year - Rs $1000 /=$

Please make cheques payable to

"Sri Lanka College of Obstetricians and Gynaecologists"

For information related to the Journal please contact:

SLCOG office

No 112, Model Farm Road

Colombo 8

Sri Lanka.

Manuscripts can be submitted on E-mail to:

deepalsenaka@yahoo.co.uk

Instructions to authors can be downloaded

from the Journal website:

www.slcog.lk 